\title{
Income Convergence in the Asia-Pacific Region
}

\author{
Leo Michelis \\ Ryerson University \\ Simon Neaime \\ American University of Beirut
}

\begin{abstract}
This paper uses the concepts of $\sigma$-convergence and $\beta$-convergence to evaluate empirically the hypothesis of income convergence in the Asia-Pacific region, and its subsets of East Asia and ASEAN during the period 1960-1999. Because of the East Asian financial crisis in the late 1990s, the analysis is carried out sequentially, first for the period 1960-1990 and then for the period 1960-1999. For the former period, we find evidence of conditional $\beta$-convergence in a group of 17 APEC countries and in 10 EASTASIA countries. No evidence of income convergence is found for the ASEAN group of countries. For the latter period, there is weak evidence of conditional $\beta$ convergence in a group of 16 APEC countries, and much weaker evidence of income convergence in EASTASIA. We attribute this finding to the damaging effects of the financial crisis in the second half of the 1990s. Also, the empirical evidence shows that openness to international trade is statistically the most important variable for sustaining economic growth in the Asia-Pacific region. Of the other variables macroeconomic stability has a positive impact on growth, while government spending and population growth have a negative effect in general.
\end{abstract}

- JEL Classification: 011, 047

- Key words: APEC, economic growth, economic integration, regional convergence

\footnotetext{
*Corresponding address: Leo Michelis, Department of Economics Ryerson University, Toronto, Canada, E-mail: michelis@acs.ryerson.ca, Tel: (416) 979-5000 ext. 7321, Fax: (416) 979-5289. Simon Neaime, Department of Economics and the Institute of Financial Economics American University of Beirut Beirut, Lebanon, E-mail: sn01@aub.edu.lb (C2004-Center for International Economics, Sejong Institution, All Rights Reserved.
} 


\section{Introduction}

Even though the sources of economic growth and growth accounting in the Asia-Pacific region are well documented in several studies, the literature on income convergence among the economies in the region is rather thin (e.g., see, World Bank (1993), The East Asian Miracle, and references therein). Yet, the subject of income convergence is an important one because it deals with the issue of sustained economic growth and the extend to which per capita income levels or living standards in low or middle income economies tend to converge to the level of high income economies over time. This paper contributes to the literature of income convergence in the Asia-Pacific region, which is the habitat of over a billion people. Specifically, we use the concepts of $\sigma$-convergence and $\beta$ convergence and data for the period 1960-1999 to evaluate empirically the hypothesis of income convergence within three groups of the Asia-Pacific region: 17 APEC $^{1}$ countries, a subset of 10 East Asian economies, and a subset of 5 members of the Association of South East Asia Nations (ASEAN) defined below.

The Asia-Pacific region is a collection of countries that includes the developing economies of East and Southeast Asia and the Pacific Islands, Japan, Australia, New Zealand, the North American economies and certain South American countries such as Chile and Peru. The World Bank (1995, p. 248) defines "East Asia and the Pacific" to mean a list of countries which includes a total of 34 "low", "middle" and "high" income economies.

The Asia Pacific economic Cooperation (APEC) was established in 1989 in response to growing interdependence among the Asia-Pacific economies. Initially it had 12 members, but since 1989 it has expanded its membership to include 21 countries: the 17 countries studied in this paper (Australia, Canada, Chile, China, Hong Kong, Indonesia, Japan, Korea, Malaysia, Mexico, New Zealand, Papua New Guinea, Philippines, Singapore, Taiwan, Thailand and the US) plus Brunei Darussalam, Peru, Russia, and Vietnam. Due to data availability, we do not include the latter four countries in our analysis. Further Peru, Russia and Vietnam are relatively new members of APEC that have had historically weak trade links with the rest of the other Asia-Pacific countries. Similar arguments can be made about China. However, China supported market-oriented reforms and trade with the rest of the world since the late 1970s under the regime of Deng Xiaping (see World Bank (1995 p. 144)). For this reason, and the historical importance of China in the Asia-Pacific region, we, like other studies, include China in our analysis. APEC is, at present, a multilateral economic forum in which the member countries communicate with each other over economic issues relating to trade liberalization in goods and services, investment, macroeconomic stability and government policies. There is neither a formal agreement nor a legal and institutional framework to support it, as one finds in the context of the European Union (EU) or the North American Free Trade Agreement (NAFTA). 
In the literature one finds different subsets of countries being studied to satisfy the analytical and empirical needs of the researchers, and the main focus of analysis has been the East Asian economies. Among others, Yamazawa (1992) gives a statistical overview of the growth pattern of ten East Asian economies, Australia Canada and the US and compares them to the European Union (EU) and the world as a whole over the period 1960-1990. He identifies East Asia as the core of the region's growth and concludes that a regime of free trade is needed to sustain East Asian growth.

The World Bank's (1993) report "The East Asian Miracle" analyses economic growth and public policy for the period 1965 to 1990 in eight high performing East Asian economies. ${ }^{2}$ The report claims that sustained growth in these countries is the result of macroeconomic stability, human capital formation, openness to international trade and private investment and competition.

Islam and Chowdhury (1997) examine the history of the Asia-Pacific economic development and the emergence of an integrated Asia-Pacific economy, through trade, foreign direct investment (FDI) and labour migration in the four newly industrialized economies (NIEs)-Hong Kong, Singapore, South Korea and Taiwan-, the four members of the Association of South East Asian Nations (ASEAN4)-Indonesia, Malaysia, the Philippines and Thailand-and China. These authors argue that the process of economic integration in this region is "market driven" and is not motivated by political or monetary union considerations like in the EU. Looking at the data from the 1960s to the early 1990s, the conclusions drawn are (a) the East Asian economies reduced their dependence on the US markets in the latter part of the 1980s, and (b) the share of intra-regional trade within the East Asian economies rose significantly after 1985.

The Asia-Pacific economies have forged closer regional linkages through extensive trade, FDI and migration from the early 1960s to the present. In fact, over this period the export-orientation of the Asia Pacific region has gone up quite markedly. In the case of the NIEs, exports as a proportion of GDP have gone up from 26 percent to 72.1 percent; in the ASEAN4, they have risen from 27 percent to 35.8 percent; while in China they have gone up from 6.8 percent to 15 percent; (International Economic Data Bank, Australian National University). Also, the

${ }^{2}$ The eight countries are Hong Kong, Indonesia, Japan, Malaysia, Singapore, South Korea, Taiwan and Thailand. 
Asia-Pacific region has been one of the fastest growing in the world in terms of economic growth. During 1980-1994, real GDP growth in the APEC countries was 3.6 percent higher than in the EU. However, within the APEC group the Asian economies grew much faster than the North American economies. For instance, China's real GDP per capita growth averaged 9.6 percent from 1980 to 1994. The NIEs were close behind at 6.5 percent. In contrast, the largest economies grew at much slower rates: North America and Japan at 2.8 percent on average. Canada's GDP grew at 1.6 percent over the same period (Industry Canada, Spring 1997).

High GDP growth rates in the Asian economies over the past four decades has meant improved standards of living and prosperity for over a billion people in that part of the world. Per capita income levels in the NIEs have almost reached those of the industrialized countries in Europe and North America. A key question is whether such high rates of growth in the Asian economies can be sustained into the future so that the level of economic development in these countries converges to that of the developed economies of North America, Europe, and Japan.

The purpose of this paper is an empirical investigation of the real per capita GDP convergence among 17 APEC economies and its two subsets of EASTASIA and ASEAN. The APEC group consists of the four NIEs, the ASEAN4, China, Japan, Papua New Guinea, Chile, Canada, Mexico, the USA, Australia and New Zealand. EASTASIA consists of the four NIEs, the ASEAN4, China and Japan. ASEAN consists of ASEAN4 plus Singapore. Economic growth is measured by the rate of growth of real per capita GDP in each country, denoted GY, for the decades of the 1960s, 1970s, 1980s, and 1990 s. To examine the issue of convergence we employ the well-known concepts of $\sigma$-convergence and $\beta$-convergence.

The concept of $\sigma$-convergence examines the behavior of cross-sectional standard deviation of real per capita GDPs over time. A reduction in the cross sectional standard deviation of GDPs over time is interpreted as evidence of income convergence. The concept of $\beta$-convergence was introduced in the literature by Barro and Sala-i-Martin $(1991,1992)$ and derives from the transitional dynamics of the neoclassical growth model. In this case, the finding of mean reversion in GDP growth rates in a cross section of countries is interpreted as evidence of income convergence among the countries.

Several empirical studies have used time series and cross section data to measure and evaluate convergence among countries and regions. Well-known papers in the 
literature include Baumol (1986), DeLong (1988), Barro and Sala-i-Martin (1991), Sala-i-Martin (1996), Ben-David (1993), Neven and Gouyette (1995) and Cheshire and Carbonaro (1995) ${ }^{3}$.

There are three important features that make this study different form other studies in the literature on the Asia-Pacific region. First, aside from the World Bank (1993) report that deals briefly with the subject of income convergence in the eight high performing Asian economies mentioned earlier, our paper provides a systematic approach of the issue of economic convergence in the Asia-Pacific region and a subset of 10 major East Asian economies. We also investigate briefly convergence within the original 5 ASEAN countries. Second, our study uses the most recent data up to and including the year 1999. Previous studies on the AsiaPacific economies have considered data up to the early 1990s. Third, because of the financial crisis experienced by the Asian economies in the latter part of the $1990 \mathrm{~s}$, we carry out our analysis sequentially. In so far as $\beta$-convergence is concerned, we first analyze the data for the three decades of the 1960s, 1970s and 1980s, and then we include the decade of the 1990s to investigate the effect of the financial crisis on income convergence in the Asia-Pacific region.

The rest of the paper is organized as follows. In Section II, we state some factors that may explain the high growth rates in the Asian economies. These range from high savings to geography, government policies, and macroeconomic stability. In Section III we discuss the concepts of economic convergence and divergence and give the precise definitions of $\sigma$-convergence and $\beta$-convergence. In Section IV, we describe the data to be used in our estimation as well as our empirical model. In Section V, we discuss the empirical results of the paper. Section VI concludes the paper.

\footnotetext{
${ }^{3}$ Baumol (1986) reported evidence in support of convergence among a subset of developed countries, but convergence could not be confirmed. DeLong (1988), using a larger sample of industrialized countries, has found divergence. Barro and Sala-i-Martin (1991) have found regional convergence among the US states during the period 1880-1988 and for a set of European regions during the period 1950-1985. More recently, Sala-i-Martin (1996) reconfirmed the regional data from the US, Japan and a number of European Union member states. A growing empirical literature deals with convergence within the European Union. Ben-David (1993), using country data, related trade liberalization to income convergence within the European Union. His results support the convergence hypothesis that poor regions tend to grow faster than rich ones. Neven and Gouyette (1995) reported that since 1975 there has been a process of convergence among $107 \mathrm{EU}$ regions. On the other hand, Cheshire and Carbonaro (1995) using different models and 122 urban EU regions reported mixed results depending upon the specification of the model.
} 


\section{Reasons for the East Asian Growth}

Despite the absence of a region-wide institutional framework to coordinate economic integration and convergence among Asia-Pacific economies, there has been impressive interdependent growth in the East Asian economies. What may be the reasons for this East Asian growth? Several reasons have been advanced in the literature, none of which is the dominant one but all of them together may account for this Asian growth.

One reason is that East Asian growth is due to high saving rates. Saving rates in East Asian countries are much higher than in North America. High saving rates mean higher investment rates, which in turn, mean higher growth rates of output. It is not clear as to the cause of high saving rates in this part of the world. Perhaps, this is due to culture and habit persistence. East Asian cultures may be simply more conducive to higher savings. Another factor is the absence of well functioning systems of social security. In their absence East Asian people are forced to save more.

Physical geography and climate is another factor. Most of the East Asian countries are coastal and thus benefit from easy and relatively cheap sea-based trade. Suchs (1997) reports evidence compiled by the Harvard Institute for International Development that land locked countries grew more slowly than coastal economies. Also climatic differences are important for growth. Tropical countries grew 1.3 percentage points slower than those in the temperate zone. The fact that nonagricultural tropical countries like Hong Kong and Singapore do well is probably due to the existence of efficient air conditioning in these countries.

The type of economic policies adopted by East Asian governments is considered to be a crucial factor for the success of their respective economies. Three aspects should be emphasized. First, governments have relied heavily on free markets for the allocation of resources in their economies. They have allowed the market forces of supply and demand to operate and they have used price signals rather than suppress them. Second, governments have been adaptable. In the lower income countries they have helped the flow of resources by using the financial system for the allocation of credit. This contributed to income growth and the development of institutions that favor market solutions to economic problems. Third, governments have adopted policies that have been export oriented. Openness is a decisive factor for rapid growth. Suchs (1997) reports that open economies grew by 1.2 percent per year faster than closed economies controlling for other factors. 
Macroeconomic stability and political stability are two main factors that have contributed to the sustained East Asian growth. All of the East Asian countries favor price stability and have low tolerance for inflation. Based on survey data from an international poll on inflation, China and Singapore showed the strongest aversion to inflation (Fischer 1986). Thus, despite the recent financial problems experienced by some East Asian economies there has been a long period of macroeconomic stability in this region that has contributed to rapid economic growth. This has been enhanced by peace and political stability that have helped democracy and the rule of law to operate, both of which are crucial for the proper functioning of market economies.

Finally demographic factors are important for growth. As the development process continued, East Asian countries experienced lower death rates, perhaps due to advances in medicine that reduce mortality rates. This meant higher population growth in this part of the world. In the standard neoclassical model with labour and physical capital, higher population growth lowers income because the existing capital has to be shared more thinly over the population of workers. This is also true when the model is augmented to include human capital, which has to be spread more thinly, implying that higher population growth lowers total factor productivity.

\section{Measuring Convergence}

In this section we outline several economic reasons for converging or diverging economies and state the measures of convergence that will be used in the empirical analysis. Convergence of two or more economic series, such as per capita output in different regions, is said to occur if the difference between the series becomes arbitrarily small or tends to some constant as time elapses. For random series, stochastic convergence requires that the probability the two series differ by a specified amount becomes arbitrarily small in the limit. If convergence fails to obtain we say that the series diverge.

Economic convergence is an important issue in growth theory and development economics. If growth rates in real per capita output across countries converge over time, then poor countries tend to develop faster than rich ones and catch-up with them eventually. This issue has given rise to the convergence hypothesis of whether poor regions or countries have the tendency to grow faster than rich ones 
(e.g. see Barro, 1991).

Economic theory is not entirely supportive of the convergence hypothesis. Whereas the standard neoclassical growth model predicts economic convergence, the more recent endogenous growth models reject convergence in general. In the neoclassical growth models of Solow (1956), Cass (1965) and Koopmans (1965), convergence is a natural outcome of exogenous technical change that migrates across countries with similar preferences and technology. Under the usual assumption of diminishing returns to reproducible capital, poor countries with low capital-labour ratios have high marginal products of capital and therefore tend to grow faster than rich countries with high capital-labour ratios. Moreover, free mobility of capital and labour across countries or regions will bid away differences in factor returns and thus factor incomes will converge to their steady-state values over time, at which point convergence ceases to be operational. Any observed differences in steady-state incomes should reflect region-specific characteristics such as differences in human capital, natural amenities or cost of living differences (see Levine and Renelt (1992) and Sherwood-Call (1996)). Hence, the neoclassical growth model is consistent with strong economic convergence across different countries or regions.

In contrast, the new endogenous growth theories, pioneered primarily by the theoretical work of Romer (1986) and Lucas (1988), are less optimistic about economic convergence, and in general predict regional disparities or economic divergence. The new theories assume constant returns to scale with respect to a broad measure of capital that includes both physical and human capital that is accumulated through formal and informal education, training and experience. According to Romer, knowledge spillovers from one firm have positive effects on the production possibilities of other firms. These spillovers increase the return to human capital in regions with large amounts of physical capital. Lucas argues that the returns to skilled labour may be higher in regions with large concentration of skilled workers due to external economics of scale. In this situation skilled workers would migrate to regions with other skilled workers, thereby causing income in these regions to increase and diverge relative to income in other less developed regions. This result of economic divergence is quite different from the equalizing effect of labour migration on factor incomes in the standard neoclassical model. Economic divergence and regional disparities have also been predicted in a different setting by Krugman (1991). In his model a developed region coexists with a less developed one in a pattern that depends on transportation costs 
and returns to scale. ${ }^{4}$

In this study, we consider two well-known measures of convergence: $\sigma$ convergence and $\beta$-convergence. The concept of $\sigma$-convergence is concerned with the behaviour over time of the cross-sectional standard deviation of real per capita output, income or some other relevant variable used to measure overall economic performance. Given a data set, if there is a decline in the cross-sectional standard deviation over time, then this is interpreted as evidence in support of convergence. This measure has been used by the European Commission in its reports of regional development in the EU.

The measure of $\beta$-convergence was suggested by Barro and Sala-i-Martin $(1991,1992)$ and derives as an approximation of the transitional dynamics of the standard neoclassical growth model. Briefly, following Barro and Sala-i-Martin (1991), the average growth rate of per capita output, $y$, in the time interval $(0, T)$, is given by the expression,

$$
\frac{1}{T} \log \frac{y_{T}}{y_{0}}=\alpha-\frac{1-e^{-\beta T}}{T} \log \frac{y_{0}}{y^{*}}
$$

where $\alpha$ is a constant and the positive parameter $\beta$ depends on the technology and preference parameters of the model and controls the speed of adjustment of $y$ to its steady state value $y^{*}$. The larger is $\beta$ the greater is the response of the average growth rate of $y$ to the gap between $y_{0}$ and $y^{*}$, that is the faster is the convergence to the steady state.

The model implies conditional convergence in the sense that what matters is $y_{0}$ relative to the steady state values of $y^{*}$ which may differ across regions. For this reason, in order to properly identify $\beta$ in empirical work, it is necessary to control for cross-sectional differences in steady state values. On the other hand, if crosssectional differences can be reasonably ignored, then equation (1) gives a form of unconditional or absolute $\beta$-convergence.

\footnotetext{
${ }^{4}$ It should be noted that the prediction of economic divergence in the endogenous growth theories is model-specific. Tamura's (1991) endogenous growth model produces per capita income convergence that is the result of human capital convergence. The latter is the outcome of knowledge spillovers to economic agents with different endowments of human capital. Knowledge spillovers cause below average human capital agents to grow faster than above average human capital agents thereby causing human capital convergence which results in income convergence. For this reason, if the convergence hypothesis is tested and rejected by a given data set no clear conclusion can be drawn in favour of the new growth theories. Rather, the empirical evidence should be interpreted with caution in the particular context of the empirical work.
} 


\section{Data Sources and the Empirical Model}

The economic data for the period 1960-1990 were obtained from the Penn World Tables through the NBER website (www.nber.org) and then were extended from various sources to complete the 1990-1999 period. The schooling data were obtained from an updated version of Barro and Lee (1996) available on the NBER website.

Specifically, a panel of cross section and annual time series data for 17 AsianPacific countries were used for the empirical analysis for the period 1960 to 1990. The countries were: Australia, Canada, Chile, China, Hong Kong, Indonesia, Japan, Korea, Malaysia, Mexico, New Zealand, Papua New Guinea, Philippines, Singapore, Taiwan, Thailand and the US. The description and sources of the data are as follows. GY: growth of real per capita GDP measured every 5-, 10- or 30year time interval of annual data, obtained from NBER; Penn World Tables, Mark 5.6. INY: initial level of real per capita GDP at the beginning of every 5-, 10- or 30-year period, obtained from NBER; Penn World Tables, Mark 5.6. GP: average annual population growth every 5-, 10- or 30-year period, obtained from NBER; Penn World Tables, Mark 5.6. SCL: average schooling years in the total population for every 5-, 10-, or 30-year period, obtained from Barro and Lee (1996). G: average share of government spending for every 5-, 10- or 30-year period, obtained from NBER; Penn World Tables, Mark 5.6. IINF: inverse of the inflation rate for every 5-, 10- or 30- year period, obtained from NBER; Penn World Tables, Mark 5.6. OPN: openness, measured by the average of (exports +imports)/GDP for every 5-, 10- or 30-year period, obtained from NBER; Penn World Tables, Mark 5.6.

For the period 1960-1999, only 16 Asia-Pacific economies were studied. Papua New Guinea was dropped from the sample due to lack of data availability in the 1990s. The data for the period 1990-1999 were obtained from the APEC secretariat website (www.apecsec.org.sg) except for the following: US government spending was obtained from the Bureau of Economic Analysis, and Thailand's government spending from the CIER website (www.cier.edu.tw).

All the economic data were expressed in 1990 US dollars using purchasing power parity exchange rates. Also, when the data were pooled, we constructed three dummy variables to capture the effect of the different decades on the process of economic growth in the Asia-Pacific economies.

Overall, the variables that were used to explain growth in the Asia-Pacific 
countries belong to four broad categories: (a) initial conditions, captured by initial real per capita GDP and schooling attainment, (b) policy variables, measured by economic openness, and government spending, (c) macro economic stability, measured by the reciprocal of the inflation rate, (d) demography, measured by population growth. The empirical results were obtained based on different empirical versions of model (1) extended by a vector of variables $\mathrm{Z}$ to account for conditional convergence:

$$
\frac{1}{T} \log \frac{y_{i, T}}{y_{i, 0}}=\alpha+\gamma \log y_{i, 0}+\phi Z_{i, T}+u_{i, T} \quad i=1, \ldots \ldots, n
$$

where $y_{i, T}=$ the real per capita GDP growth rate for country $i$ in year T.

$y_{i, 0}=$ the initial period real per capital GDP for country $i$.

$\frac{1}{T} \log \frac{y_{i, T}}{y_{i, 0}}=\mathrm{GY}=$ the growth rate of $\mathrm{y}$ in the interval $(0, \mathrm{~T})$.

$Z_{i, T}=$ a set of explanatory variables from the categories (a), (b), (c), and (d) above, intended to keep the steady-state characteristics of the countries in the sample constant, as well as three dummy variables to capture decade effects for the 1970s and 1980s and 1990s.

$u_{i, T}=$ a random error term.

$$
\gamma=-\frac{1-e^{-\beta T}}{T} \text {. }
$$

The parameter $\gamma=-\frac{1-e^{-\beta T}}{T}$ contains the convergence parameter $\beta$. For a given $T$, the higher is $\beta$ the higher is $\gamma$ in absolute value. It is also clear from this expression that as long as the parameter $\beta$ is positive, the parameter $\gamma$ will be negative, and hence a significantly negative estimate of $\gamma$ is consistent with the hypothesis of income convergence in our cross section of countries. Of the other regression parameters, $\alpha$ is a regression constant and $\phi$ is a vector of unknown regression parameters that capture the marginal effect on the growth rate of real per capita GDP due to marginal changes in the variables in $Z$. If the vector of parameters $\phi$ is set equal to zero, then equation (2) can be used to analyze unconditional or absolute convergence. Since our sample contains a diverse cross section of countries with different steady state characteristics, we concentrate on analyzing and reporting the results for conditional convergence below. The estimated magnitude, sign and statistical significance of the $\gamma$ and $\phi$ coefficients is a major concern of the present paper.

Heteroscedasticity consistent Least Squares for cross section and panel (pooled) regression techniques were used to estimate the empirical models. First, cross 
section regressions for every 5 years, 10 years and the whole sample intervals were estimated. Second, the data for 17 or 16 Asia-Pacific and 10 East Asian countries were combined and panel regression models were estimated in order to get more efficient parameter estimates.

\section{Empirical Results}

In this section we present and analyze the empirical results for $\sigma$-convergence and $\beta$-convergence for three groups of the Asia-Pacific region defined above: the APEC group (APEC(16) or APEC(17)), the EASTASIA group, and the ASEAN group. It is interesting to study convergence in the latter two subgroups alone. EAESTASIA has been the core of high growth in the Asia-Pacific region, and thus studying convergence in this subgroup without including the North American economies, Australia and New Zealand is of some interest in itself and may provide some new insights about the process of economic convergence in this particular region. Similar arguments apply for the ASEAN subgroup. Further, even though the interdependent growth of East Asia has emerged without a formal integration framework, ASEAN is an exception, because it was formed in 1967 based on a formal framework for economic cooperation. Hence, the process of economic integration may have gone further within the ASEAN group.

\section{A. $\sigma$-convergence}

Figure 1 shows the cross sectional standard deviations of the natural logarithms (logs) of the real per capita GDP at 5-year intervals from 1960 to 1999 for the three groups of the Asia-Pacific region: APEC(16), ASEAN and EASTASIA. As seen in Figure 1, the cross sectional standard deviations of the log-GDPs for the APEC(16) counties have declined from 1965 through to 1990, but in the early 1990s they started increasing, with a greater propensity in the 1995-1999 subperiod. The latter finding is not surprising, since the 1995-1999 sub-period includes the 1997-98 period of financial crisis in most East Asian countries that plunged their economies into economic instability and recession. Consequently, using the criterion of $\sigma$-convergence, there is some evidence of economic convergence within the APEC(16) group of countries. However, this is not the case for the ASEAN and EASTASIA sub-groups. In both sub-groups of countries the cross sectional standard deviations of the logs of real per capita GDPs have increased throughout the sample period from 1960 to 1999 . The increase in the standard deviations was 
Figure 1. Standard Deviations of log-GDPs.

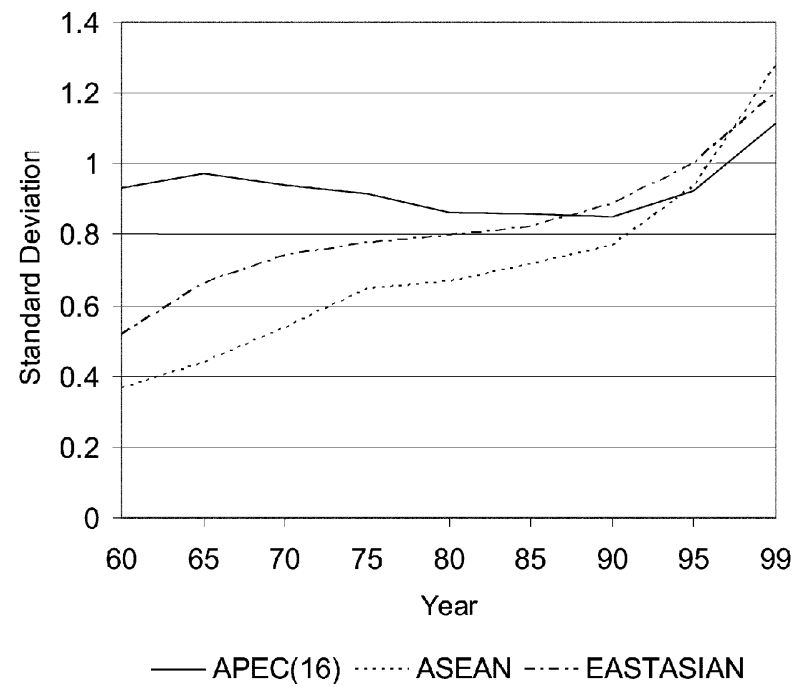

rather moderate in the 1960s, 1970s and 1980s, but it accelerated in the 1990s, even more so for the ASEAN countries. Clearly, there does not seem to be evidence of $\sigma$-convergence within ASEAN or EASTASIA during the period 1960-1999. On the contrary, the evidence in the data points to economic divergence in the two sub-groups of countries. A plausible explanation for this result is the fact that for most of the sample period the ASEAN and EASTASIA economies have experienced high average growth rates that nonetheless have been more volatile than the typically lower average growth rates of the developed economies of Europe, North America and Australia. A main reason for this may be the different stages of economic development that the East Asian economies have gone through, and the diversity of their economic structures that respond differently to random economic disturbances. For instance, Korea, Thailand and Taiwan, being oil importers, faced sharp declines in their terms of trade during the oil price shocks of 1973-74 and 1980-81. As oil exporters, Indonesia and Malaysia benefited form the oil price increases but faced severe difficulties in 1986 due to declining oil and commodity prices and rising interest rates. On the other hand oil price increases had minor direct impact on Hong Kong and Singapore, which depend primarily on manufactured exports, but both are vulnerable to international business cycles.

Figure 2 plots an alternative measure of $\sigma$-convergence in terms of the 5 -year cross sectional standard deviation of the growth rates of real per capita GDPs for 
Figure 2. Standard Deviations of GDP Growth: 5-year Periods.

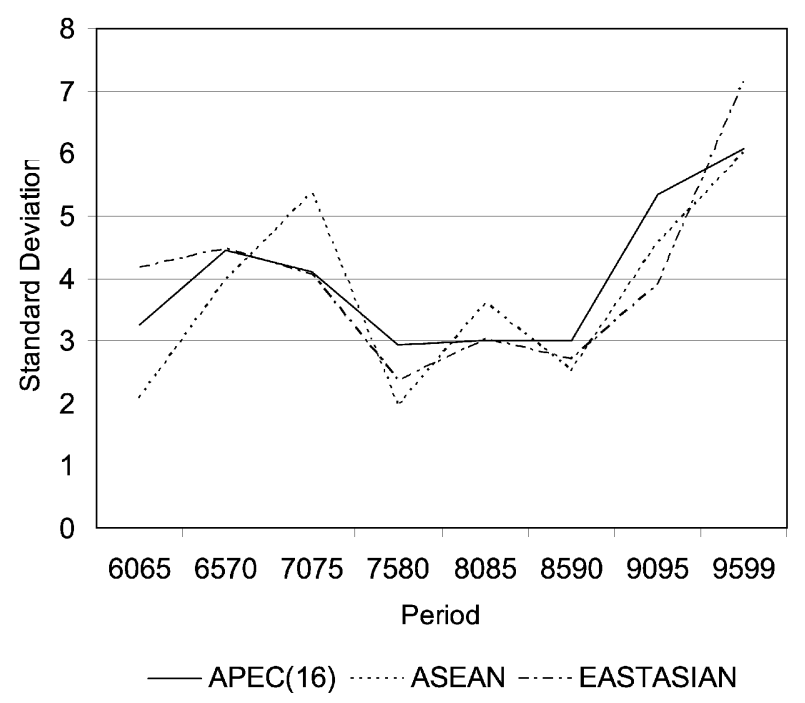

the three groups of economies. As was the case with the standard deviation of the log-GDPs in Figure 1, the APEC(16) counties show converging growth rates from 1965 to 1990 and diverging growth rates in the 1990s. The same is true on average for the growth rates of the 10 EASTASIA economies but their growth rates are more volatile than in the APEC(16) group as a whole. The ASEAN growth rates are the most volatile of all with no tendency for convergence, except for the 197580 and $1985-90$ sub-periods.

Clearly, the inclusion of the developed economies in the Asia-Pacific region provides an element of stability in the region and an anchor toward which the East Asian economies tend to converge, in the absence of major crises such as the East Asia financial crisis of the late 1990s.

In summary, the evidence so far is mixed with respect to $\sigma$-convergence in the Asia-Pacific region. There is partial evidence of convergence in terms of levels and growth rates of real per capita GDPs in the APEC countries, and the growth rates in the 10 EASTASIA economies, but evidence of divergence in the level of the log-GDPs of EASTASIA and the level of log-GDPs and growth rates of the 5 ASEAN economies.

As shown by Barro and Sala-i-Martin (1995, pp. 384-85), $\sigma$-convergence is only a sufficient but not necessary condition for $\beta$-convergence. In fact, $\beta$ convergence, if it exists, will tend to contribute to $\sigma$-convergence, but random regional shocks that increase the variance of the error term $u_{i t}$ in equation (2) 
above, can cause $\sigma$-convergence to fail even in the presence of $\beta$-convergence. Consequently, we can gain additional insights about the process of income convergence in the Asia-Pacific region if we study $\beta$-convergence on its own merits. We turn to this analysis next.

\section{B. $\beta$-convergence}

In this section we present and analyze the results for $\beta$-convergence. As an exploratory step we examine absolute convergence graphically and then proceed to analyze the empirical regression results for conditional $\beta$-convergence sequentially; first for the 1960-1990 period and then for the entire 1960-1999 period. This way the direct effects of the financial crisis of the late 1990s on the convergence process in the Asia-Pacific region can be seen more clearly in the second period.

Figures 3, 4 and 5 plot the log of the 1960 real per capita GDP against the annual growth rate of real per capita GDP over the 1960-1990 for the APEC(17), EASTASIA and ASEAN groups of countries defined earlier. As seen in Figure 3,

Figure 3. APEC(17): GDP Growth vs Initial GDP.

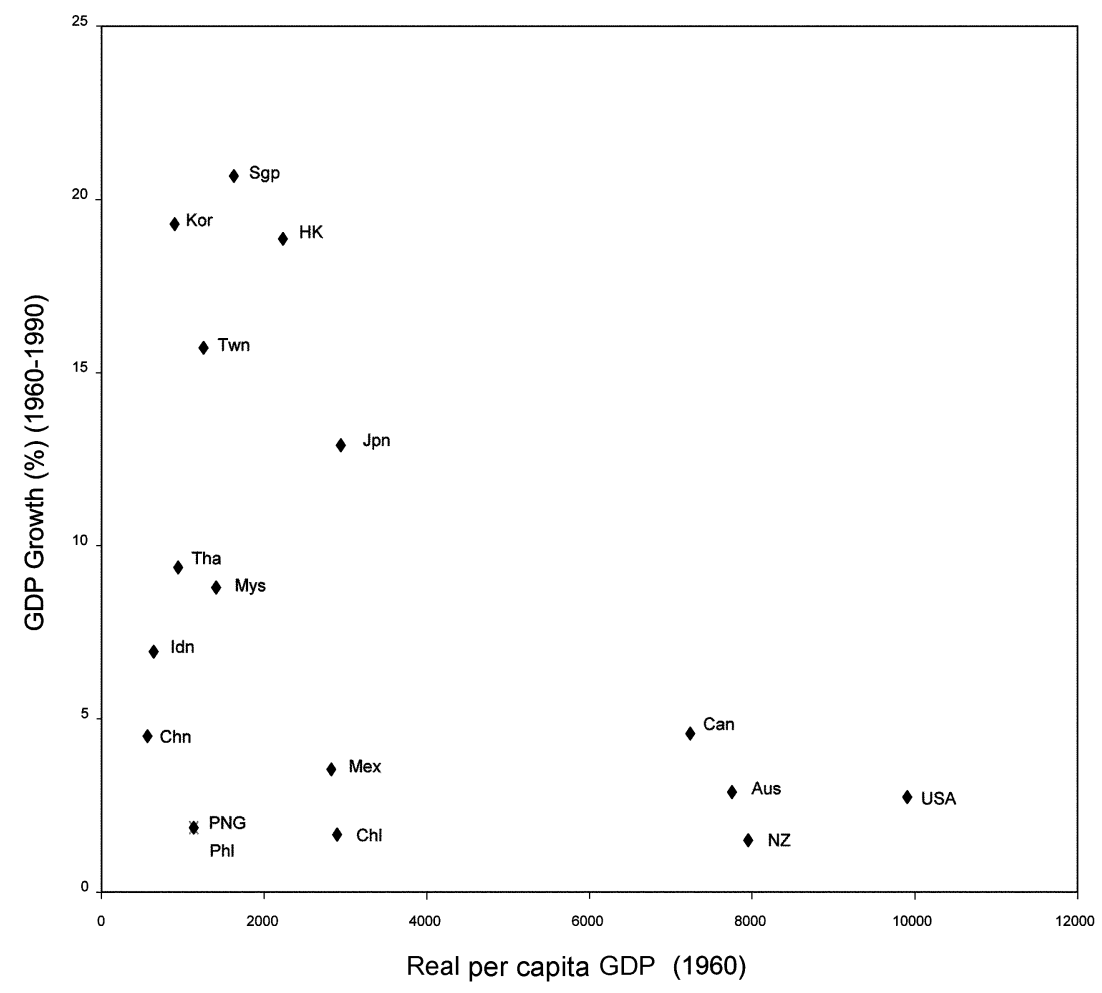


Figure 4. EASTASIA: GDP Growth vs Initial GDP.

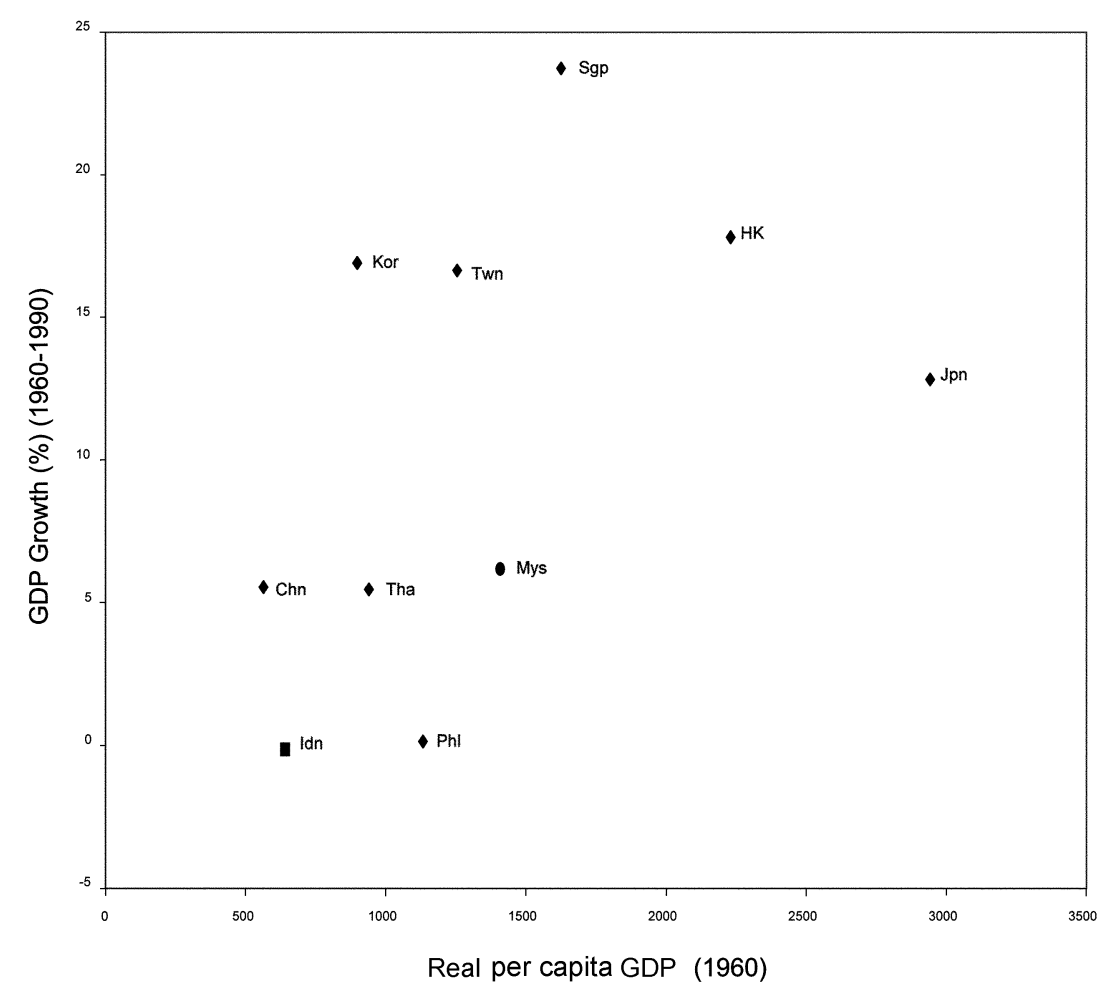

there is an inverse relationship between initial real per capita GDP and the growth rate of real per capita GDP. Consequently, the East Asian economies grew faster on average over the sample period than the developed economies of Australia, Canada, New Zealand and the US. In other words, Figure 3 supports the hypothesis of absolute convergence in our sample of the APEC(17) countries.

Figure 4 shows weaker evidence of absolute convergence for the EASTASIA economies, in that the scatter plot is more dispersed than in Figure 3 and the anchor of convergence is provided by the Japanese economy. It is also evident form Figure 4 that removing Japan from this group of the East Asia economies results in a failure of absolute $\beta$-convergence: if anything, in this case, the best fit through the data points is an upward slopping line. The same is true for the ASEAN economies as shown in Figure 5. In this case Singapore provides an outlier observation that contributes to divergence. Even without Singapore there is no evidence of absolute convergence within ASEAN4. This result should not be surprising, since ASEAN is a group of relatively high growth developing economies (save the Philippines) without a reference point of convergence like 
Figure 5. ASEAN: GDP Growth vs. Initial GDP.

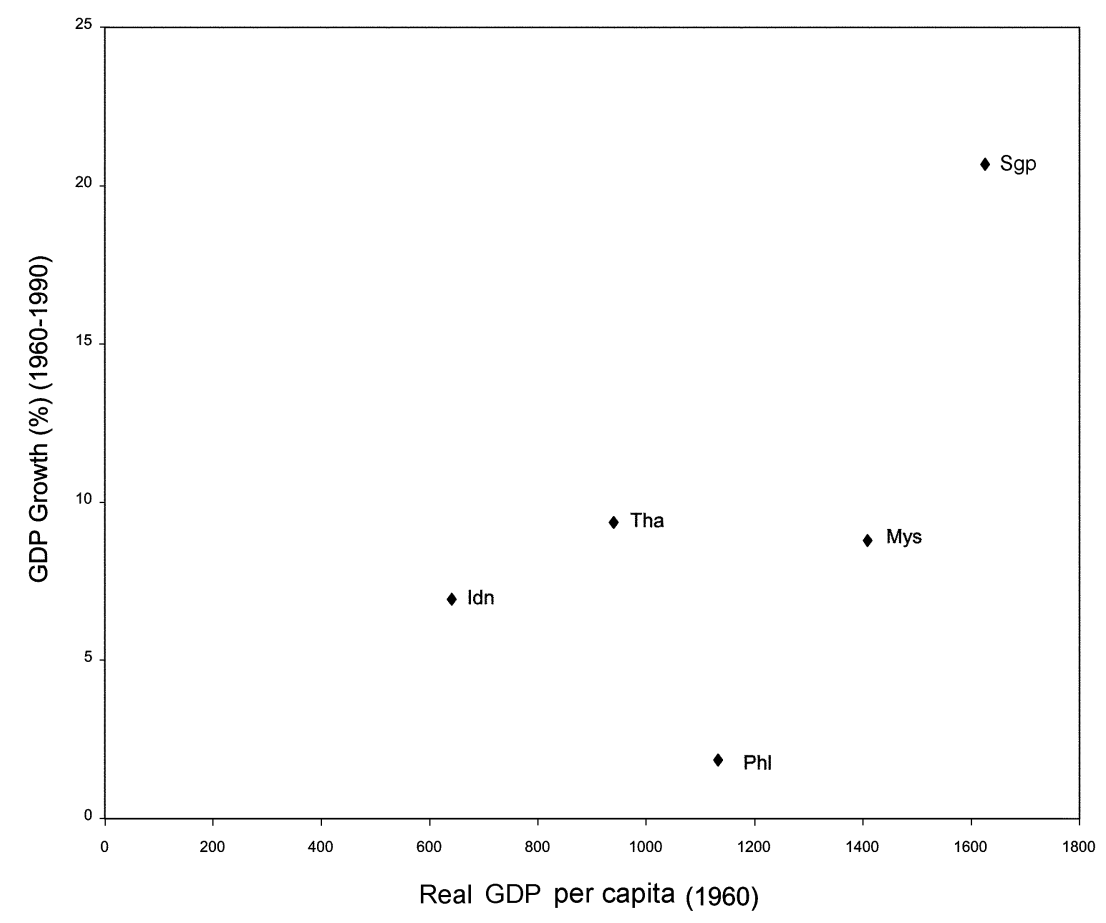

Japan or the developed economies in Figure 1. Indeed, our empirical regression results indicate lack of absolute or conditional convergence for the ASEAN countries and do not provide any new insights about this group of economies. For this reason, we do not report the regression results for the ASEAN countries. ${ }^{5}$

In the remainder of this section we use formal regression techniques to investigate the hypothesis of conditional $\beta$-convergence in the APEC and EASTASIA regions. As mentioned above, we present first the results for the period 1960-1990 and then the results for the period 1960-1999.

\section{The 1960-1990 Period}

Table 1 reports the empirical results for the 5-year interval sub-samples from 1960-1965 through to 1985-1990. The dependent variable in all regressions is average real per capita GDP growth rate for each sub-period. The explanatory variables in Z were INY, SCL, IINF, OPN and GP as defined in Section 4.

Economic growth is a long-run process that is realized over long time periods,

\footnotetext{
${ }^{5}$ These results are available from the authors upon request.
} 
Table 1. APEC(17) 1960-1990: Cross Sectional Growth Regression Periods: 60-65, 65-70, 70-75, 75-80, 80-85, 85-90

Dependent Variable: Real per capita GDP Growth

\begin{tabular}{ccccccc}
\hline Variable & GY6065 & GY6570 & GY7075 & GY7580 & GY8085 & GY8590 \\
\hline CON & 4.211 & 7.930 & 7.929 & -4.542 & 11.529 & 3.776 \\
& $(0.676)$ & $(1.253)$ & $(1.307)$ & $(-0.692)$ & $(1.751)$ & $(0.744)$ \\
INY & -0.0004 & $-0.001 * *$ & -0.0008 & -0.0006 & -0.0004 & $-0.0007 * *$ \\
& $(-0.592)$ & $(-2.223)$ & $(-1.261)$ & $(-1.645)$ & $(-1.802)$ & $(-2.216)$ \\
SCL & 0.388 & $1.138^{* *}$ & 0.658 & 1.154 & 0.034 & 1.021 \\
& $(0.534)$ & $(2.102)$ & $(0.779)$ & $(1.264)$ & $(0.067)$ & $(1.200)$ \\
IINF & -0.156 & -0.036 & 0.468 & 0.234 & -0.778 & 1.311 \\
& $(-1.818)$ & $(-0.119)$ & $(0.492)$ & $(1.485)$ & $(-0.198)$ & $(0.734)$ \\
OPN & $0.059^{* * *}$ & 0.013 & 0.019 & 0.0069 & $0.013 * *$ & $0.022 * * *$ \\
& $(3.120)$ & $(0.759)$ & $(0.829)$ & $(1.090)$ & $(2.183)$ & $(4.725)$ \\
GP & -1.327 & -1.912 & -2.572 & 2.584 & $-4.863 * *$ & -2.477 \\
& $(-0.641)$ & $(-0.868)$ & $(-1.418)$ & $(1.349)$ & $(-2.266)$ & $(-1.748)$ \\
Nobs & 17 & 17 & 17 & 17 & 17 & 17 \\
R ${ }^{2}:$ & 0.407 & 0.514 & 0.610 & 0.537 & 0.508 & 0.473 \\
F : & 1.510 & 2.333 & 3.448 & 2.557 & 2.274 & 1.981 \\
\hline
\end{tabular}

NOTES:

1. ***,**,*Statistically significant at the $1 \%, 5 \%$ and $10 \%$ level respectively.

2. The t-statistics of coefficient estimates appear in parentheses

3. The standard errors of the coefficient estimates are heteroscedasticity-consistent

longer than the five-year intervals considered in Table 1. In this sense, the results in Table 1 should be viewed as preliminary and indicative rather than definitive. They are reported here to indicate the variables that are important in explaining economic growth even over shorter time spans like 5 years.

It is clear from Table 1 that initial GDP, INY, has a negative estimated coefficient that turns out to be statistically significant at the 5 percent level in the 65-70 and 85-90 sub-periods. The negative sign is as expected and is consistent with conditional $\beta$-convergence. The negative sign on the coefficient of INY signifies conditional income convergence among the APEC(17) countries. It is justified theoretically and provides support for the transitional dynamics of the neo-classical growth model; e.g., see Barro and Sala-i-Martin (1991). Among the other explanatory variables, economic openness, OPN, turns out to be an important factor for explaining economic growth in the APEC(17) group of countries and its effect is statistically significant at the 1-, 5- and 1 percent level during the 60-65, 80-85 and 85-90 sub-periods respectively. Population growth, GP, is also significant and has the expected negative impact on growth during the first half of the 1980s. 
Table 2. APEC(17) 1960-1990:

Cross Sectional Growth Regression for the 1960s, 1970s and 1980s Dependent Variable: Real per capita GDP Growth

\begin{tabular}{ccccc}
\hline Variable & GY6070 & GY7080 & GY8090 & GY6090 \\
\hline CONST & 6.164 & 0.558 & 8.907 & 13.910 \\
& $(0.898)$ & $(0.109)$ & $(2.100)$ & $(1.335)$ \\
INY & -0.001 & -0.0007 & -0.0004 & $-0.0002 * *$ \\
& $(-1.416)$ & $(-1.130)$ & $(-1.244)$ & $(-2.244)$ \\
SCL & 1.108 & 0.879 & 0.085 & 1.075 \\
& $(1.289)$ & $(0.737)$ & $(0.123)$ & $(1.001)$ \\
IINF & 0.222 & -0.429 & $0.423 *$ & 0.284 \\
& $(0.391)$ & $(-0.384)$ & $(1.891)$ & $(1.161)$ \\
OPN & 0.019 & $0.032 * * *$ & $0.020 * * *$ & $0.044 * *$ \\
& $(1.359)$ & $(5.608)$ & $(4.097)$ & $(2.236)$ \\
GP & -1.447 & 0.430 & $-3.383 * *$ & -4.090 \\
& $(-0.597)$ & $(0.380)$ & $(-2.410)$ & $(-1.230)$ \\
Nobs & 17 & 17 & 17 & 17 \\
R $^{2}:$ & 0.442 & 0.601 & 0.636 & 0.604 \\
F $:$ & 1.743 & 3.314 & 3.844 & 3.368 \\
\hline
\end{tabular}

NOTES:

1. ***,**, *Statistically significant at the $1 \%, 5 \%$ and $10 \%$ level respectively.

2. The t-statistics of coefficient estimates appear in parentheses

3. The standard errors of the coefficient estimates are heteroscedasticity-consistent.

Table 2 reports the empirical cross section results for the 10-year intervals and the whole sample 30-year time span from 1960 to 1990. As seen from Table 2, over the 10-year time intervals the variables that are significant in explaining economic growth in the APEC(17) countries are macroeconomic stability, IINF, openness, OPN, and population growth, GP, in the 1980s. IINF as expected has a positive estimated coefficient and is statistically significant at the 10 percent level. OPN turns out to be strongly significant at the 1 percent level in the 1970s and in the 1980s (t-ratios 5.608 and 4.097 respectively) and it is estimated with the theoretically correct positive sign: the more open are the APEC economies the greater will be their economic growth. GP as before has a negative impact on economic growth and it is statistically significant at the 5 percent level in the 1980s. In terms of goodness of fit, we see that in the 1970s and 1980s, where we get some significant results, the coefficients of determination, $\mathrm{R}^{2}$, are estimated at 60 percent and 63.6 percent respectively which are quite high for cross section regressions and are indicative of good explanatory power of the estimated models.

The last column of Table 2 provides the results of the whole sample period 1960-1990. This 30-year time period spans the whole sample and it is long enough 
to capture important factors that affect economic growth. As seen in this column, INY and OPN are statistically significant at the 5 percent level and the coefficients are estimated with the correct signs. Thus, initial conditions are significant for economic growth and point to conditional convergence of national incomes across the APEC(17) countries. Economic openness again has a positive effect on economic growth over the long run and is statistically significant.

The empirical results so far have been based on the estimation of cross section regressions. Yet there are good reasons to believe that real per Capita GDP growth rates are contemporaneously correlated across the APEC countries. For example, these contemporaneous correlations may arise due to international business cycles, coordinated policy efforts among government officials of APEC countries and other missing variables that are not included in our estimated regressions. For these reasons, all the data were pooled and panel growth regressions were estimated in order to obtain more reliable and efficient estimates.

Table 3 gives the results for the panel growth regressions when the data were pooled for the 5-year and 10-year sub-periods respectively. For the 5-year interval pooled data, the second column of the Table shows that the initial GDP and economic openness have the correct sign and are statistically significant at the 1 percent level. Population growth has a negative effect on economic growth and is statistically significant at the 10 percent level. Also, government spending, G, has a negative estimated coefficient and is significant at the 5 percent level. The negative effect of $\mathrm{G}$ on real per capita growth can be viewed as a crowding out effect. That is, government spending reduces private saving and growth through the distorting effects from taxation and other government programs; e.g., see Barro (1991). ${ }^{6}$ For the 10-year interval pooled data, the third column of Table 3 shows that initial GDP and economic openness have the correct sign and enter the growth regressions significantly at the 1 percent level. Economic stability, IINF, is also estimated with the correct sign and is statistically significant at the 5 percent level.

Notice also that the results for these variables are strengthened in the case where the dummy variables D70 and D80 were included in the estimated regressions to capture the decade effects of the 1970s and 1980s respectively. Further, as seen

${ }^{6}$ Strictly speaking, this argument applies if G was government consumption alone as in Barro (1991). This would mean deducting expenditures on defense and education from total government spending to arrive at total government consumption expenditures. We were not able to do this in the present study due to lack of data availability on defense and education expenditures for the APEC countries. For this reason, $\mathrm{G}$ should be viewed as a proxy for government consumption in our study. 
Table 3. APEC(17) 1960-1990:

Panel Growth Regressions: 5-year and 10-Year panels Dependent Variable: Real per capita GDP Growth

\begin{tabular}{|c|c|c|c|}
\hline Variable & GY5 & GY10 & GY10 \\
\hline CONST & $\begin{array}{c}8.450 \\
(3.324)\end{array}$ & $\begin{array}{c}8.208 \\
(2.238)\end{array}$ & $\begin{array}{l}10.718 \\
(2.355)\end{array}$ \\
\hline INY & $\begin{array}{c}-0.0005 * * * \\
(-3.988)\end{array}$ & $\begin{array}{c}-0.0007 * * * \\
(-2.682)\end{array}$ & $\begin{array}{c}-0.0006^{* * * *} \\
(-2.838)\end{array}$ \\
\hline SCL & $\begin{array}{c}0.314 \\
(1.226)\end{array}$ & $\begin{array}{c}0.445 \\
(1.157)\end{array}$ & $\begin{array}{c}0.35 \\
(0.946)\end{array}$ \\
\hline IINF & $\begin{array}{l}-0.0444 \\
(-0.669)\end{array}$ & $\begin{array}{c}0.299 * * \\
(2.266)\end{array}$ & $\begin{array}{c}0.366^{* * *} \\
(3.110)\end{array}$ \\
\hline OPN & $\begin{array}{c}0.015^{* * *} * \\
(3.464)\end{array}$ & $\begin{array}{c}0.018 * * * \\
(3.679)\end{array}$ & $\begin{array}{c}0.021 * * * \\
(4.638)\end{array}$ \\
\hline GP & $\begin{array}{l}-0.145^{*} \\
(-1.816)\end{array}$ & $\begin{array}{c}-1.012 \\
(-1.577)\end{array}$ & $\begin{array}{c}-1.702 \\
(-1.510)\end{array}$ \\
\hline $\mathrm{G}$ & $\begin{array}{c}-0.145^{* *} \\
(-2.171)\end{array}$ & $\begin{array}{c}-0.155 \\
(-1.577)\end{array}$ & $\begin{array}{l}-0.151 * \\
(-1.789)\end{array}$ \\
\hline D70 & ---- & ---- & $\begin{array}{c}-0.895 \\
(-0.755)\end{array}$ \\
\hline D80 & ---- & ---- & $\begin{array}{c}-2.748 * * \\
(-2.058)\end{array}$ \\
\hline Nobs & 102 & 51 & 51 \\
\hline $\mathrm{R}^{2}$ & 0.337 & 0.494 & 0.568 \\
\hline $\mathrm{F}$ & 8.059 & 7.166 & 6.923 \\
\hline
\end{tabular}

NOTES:

1. ***,**, *Statistically significant at the $1 \%, 5 \%$ and $10 \%$ level respectively.

2. The t-statistics of coefficient estimates appear in parentheses.

3. The standard errors of the coefficient estimates are heteroscedasticity-consistent.

from the last column of Table 3, both decades had a negative impact on economic growth but only the decade of the 1980s is statistically significant. Perhaps, the significant negative effect for the 1980s decade reflects the fact that high growth rates cannot be sustained indefinitely in the future, and in the course of time as economic development proceeds, growth rates revert to more feasible long-run average levels. This is what is expected under the convergence hypothesis. In addition, in this estimated regression government spending, G, is statistically significant at the 10 percent level and has a negative impact on economic growth.

An interesting finding in Table 3 is the relatively high values of the t-ratios and F-statistics compared to those obtained in Tables 1 and 2. This is a result of the 
more efficient estimates delivered by the system panel regressions relative to the single equation cross section regressions in Tables 1 and 2. For example, in Table 2 when GY7080 is the dependent variable the estimated coefficient for INY is -0.0007 , which is of the same magnitude as in the GY10 column of Table 3. Yet, the t-ratio for INY in Table 2 is -1.130 and insignificant, but it is -2.682 and statistically significant in Table 3 . This means that the pooled regression in this case resulted in a reduction of the estimated standard error of the coefficient of INY by a factor of 2.37 in Table 3 compared to the single equation estimation in Table 2. Also, the statistical efficiency gained from the panel regressions is reflected more generally in the much larger and statistically significant F-ratios of Table 3 compared to the F-ratios in Tables 1 and 2. Further, the explanatory power of the estimated models in Table 3 has remained quite good despite the inclusion of additional variables compared to Tables 1 and 2. When GY10 is the dependent variable, the estimated $R^{2}$ are 49.4 percent and 56.8 percent respectively in the last two columns of Table 3 . These are quite high values given that the estimated models are cross section regressions.

Since the panel techniques provide more efficient parameter estimates, to save space in the remainder of the paper we report mainly the panel regression results.

Table 4 reports the 1960-1990 period results as well as this period's 5-year and 10-year panel results for EASTASIA. As shown in the second column of this table the coefficient for initial real per capita GDP is negative but statistically insignificant, pointing to lack of conditional $\beta$-convergence for this group of countries. This is consistent with the conclusion that we reached in Figure 2 in terms of the lack of $\sigma$-convergence in EASTASIA. All the other variables, SCL, IINF, OPN, and GP are estimated with the expected sign but are statistically insignificant. The 5-year panel results in the third column of the table are statistically stronger and indicate conditional convergence at the 1 percent level of significance. All the other variables, except the insignificant IINF, have the expected signs and are statistically significant; openness and government spending at the 1 percent level and population growth at the 5 percent level. The last column of Table 4 gives the results for the 10-year panel. Here too there is evidence of significant conditional convergence at the 1 percent level. Economic openness over the 10-year time intervals seems to be an important determinant of economic growth in the East Asian economies. Also, as before the decade of the 1980s has a significantly negative impact on growth in East Asia at the 10 percent level. Further, the inclusion of the dummy variables in the model increases the $\mathrm{R}^{2}$ to 58.4 percent. 
Table 4. EASTASIA 1960-1990: Cross Section Growth Regression for 1960-1990, and 5year and 10-year panels from 1960 to 1990 Dependent Variable: Real per capita GDP Growth

\begin{tabular}{|c|c|c|c|}
\hline Variable & GY6090 & GY5 & GY10 \\
\hline \multirow[t]{2}{*}{ CONST } & 15.449 & 9.035 & 8.019 \\
\hline & (1.026) & $(2.438)$ & (1.327) \\
\hline \multirow[t]{2}{*}{ INY } & -0.0038 & $-0.0007 * * *$ & $-0.0009 * * *$ \\
\hline & $(-0.663)$ & $(-3.477)$ & $(-2.869)$ \\
\hline \multirow[t]{2}{*}{ SCL } & 1.584 & 0.640 & 1.214 \\
\hline & $(0.986)$ & $(1.455)$ & $(1.730)$ \\
\hline \multirow[t]{2}{*}{ IINF } & 0.917 & -0.037 & -0.041 \\
\hline & $(0.685)$ & $(-0.337)$ & (0.319) \\
\hline \multirow[t]{2}{*}{ OPN } & 0.0955 & $0.021 * * *$ & $0.024 * * *$ \\
\hline & (1.349) & (4.204) & $(5.828)$ \\
\hline \multirow[t]{2}{*}{ GP } & -2.659 & $-1.665 * *$ & -2.043 \\
\hline & $(-1.049)$ & $(-1.863)$ & $(-2.043)^{*}$ \\
\hline \multirow[t]{2}{*}{ G } & ---- & $-0.258 * * *$ & -0.111 \\
\hline & & $(-3.198)$ & $(-0.859)$ \\
\hline \multirow[t]{2}{*}{ D70 } & ---- & ---- & -0.814 \\
\hline & & & $(-0.580)$ \\
\hline \multirow[t]{2}{*}{ D80 } & ---- & ---- & $-3.783^{*}$ \\
\hline & & & $(-1.929)$ \\
\hline Nobs & 10 & 60 & 30 \\
\hline $\mathrm{R}^{2}$ & 0.617 & 0.395 & 0.584 \\
\hline $\mathrm{F}$ & 1.293 & 5.777 & 5.914 \\
\hline
\end{tabular}

NOTES:

1. ***, **, *Statistically significant at the $1 \%, 5 \%$ and $10 \%$ level respectively.

2. The t-statistics of coefficient estimates appear in parentheses.

3. The standard errors of the coefficient estimates are heteroscedasticity-consistent.

\section{The 1960-1999 Period}

The financial crisis of the late 1990s contributed to economic instability and economic recession in East Asia. In order to gain some insight on the effects of the financial crisis on the process of economic convergence in the Asia-Pacific region, we present and discuss separate regression results for the 1960-1999 period for the APEC(16) and EASTASIA groups of countries.

Table 5 reports the empirical results for APEC(16) during the 1960-1999 period. In this case the coefficient of initial real GDP is only significant at the 10 percent level and is not significant at all in the 10-year panel. Schooling, SCL, and economic stability, IINF, are also statistically insignificant. However, as in all previous cases, openness to international trade is an important and strongly 
Table 5. APEC(16) 1960-1999: Cross section Growth Regression for 1960-1999, and 5-year and 10-year panels from 1960 to 1999 Dependent Variable: Real per capita GDP Growth

\begin{tabular}{cccc}
\hline Variable & GY6099 & GY5 & GY10 \\
\hline CONST & 21.900 & 4.468 & 11.086 \\
& $(2.611)$ & $(1.437)$ & $(3.302)$ \\
INY & $-0.0007^{*}$ & $-0.0003^{*}$ & -0.0002 \\
& $(-2.049)$ & $(-1.900)$ & $(-1.276)$ \\
SCL & 0.074 & 0.158 & 0.191 \\
& $(0.075)$ & $(0.427)$ & $(0.502)$ \\
IINF & -0.282 & -0.028 & -0.021 \\
& $(-0.893)$ & $(-0.501)$ & $(-0.146)$ \\
OPN & $0.088^{* * *}$ & $0.014^{* *}$ & $0.027^{* * *}$ \\
& $(7.948)$ & $(2.566)$ & $(5.116)$ \\
GP & $-9.277^{* * *}$ & -0.449 & $-1.983^{* *}$ \\
& $(-4.044)$ & $(-0.531)$ & $(-2.282)$ \\
G & ---- & -0.033 & $-0.186^{* * *}$ \\
& & $(-0.573)$ & $(-3.756)$ \\
D70 & ---- & --- & -1.105 \\
& & & $(-0.966)$ \\
D80 & ---- & ---- & $-3.587^{* * *}$ \\
& & & $(-2.863)$ \\
D90 & ---- & --- & $-5.154^{* * *}$ \\
& & & $(-2.980)$ \\
Nobs & & 128 & 64 \\
$\mathrm{R}^{2}$ & 16 & 0.097 & 0.461 \\
F & 0.392 & 2.163 & 5.131 \\
\hline
\end{tabular}

\section{NOTES:}

1. ***,**, *Statistically significant at the $1 \%, 5 \%$ and $10 \%$ level respectively.

2. The t-statistics of coefficient estimates appear in parentheses.

3. The standard errors of the coefficient estimates are heteroscedasticity-consistent.

significant variable in explaining economic growth across the APEC(16) countries. Population growth is also negative and significant for the entire period 1960-1990 and for the 10-year panel cases at the 1- and 5 percent level respectively. Government spending as before has a negative impact on growth in the 5- and 10-year panels but it is statistically significant in the 10-year panel at the 1 percent level. Interestingly, the estimated coefficients of the dummy variables for the decades of the 1980s and 1990s are negative and strongly significant at the 1 percent level for the first time. It seems that the financial crisis of the late 1990s in Asia has made the time effect on growth in the APEC(16) region quantitatively 
Table 6. EASTASIA 1960-1999:

Cross section Growth Regression for 1960-1999, and 5-year and 10-year panels from 1960 to 1999

Dependent Variable: Real per capita GDP Growth

\begin{tabular}{|c|c|c|c|}
\hline Variable & GY6099 & GY5 & GY10 \\
\hline \multirow[t]{2}{*}{ CONST } & 5.053 & 4.468 & 7.110 \\
\hline & (1.469) & $(0.664)$ & (1.269) \\
\hline \multirow[t]{2}{*}{ INY } & -0.0005 & $-0.0005^{*}$ & -0.0001 \\
\hline & $(-0.882)$ & $(-2.001)$ & $(-0.481)$ \\
\hline \multirow[t]{2}{*}{ SCL } & 2.196 & 0.263 & 0.756 \\
\hline & $(0.962)$ & $(0.403)$ & (1.185) \\
\hline \multirow[t]{2}{*}{ IINF } & -0.583 & -0.033 & -0.035 \\
\hline & $(-0.337)$ & $(-0.332)$ & $(-0.287)$ \\
\hline \multirow[t]{2}{*}{ OPN } & 0.104 & $0.016 * *$ & $0.022 * * *$ \\
\hline & (1.409) & $(2.270)$ & (3.741) \\
\hline \multirow[t]{2}{*}{ GP } & $-9.223 * *$ & -0.619 & -1.518 \\
\hline & $(-2.301)$ & $(-0.564)$ & $(-1.499)$ \\
\hline \multirow[t]{2}{*}{ G } & ---- & -0.049 & -0.072 \\
\hline & & $(-0.178)$ & $(-0.462)$ \\
\hline \multirow[t]{2}{*}{ D70 } & ---- & ---- & -1.117 \\
\hline & & & $(-0.772)$ \\
\hline \multirow[t]{2}{*}{ D80 } & ---- & ---- & $-4.720 * *$ \\
\hline & & & $(-2.582)$ \\
\hline \multirow[t]{2}{*}{ D90 } & ---- & ---- & $-6.979 * * *$ \\
\hline & & & $(-2.865)$ \\
\hline Nobs & 10 & 30 & 40 \\
\hline $\mathrm{R}^{2}$ & 0.413 & 0.584 & 0.495 \\
\hline $\mathrm{F}$ & 3.484 & 3.689 & 3.226 \\
\hline
\end{tabular}

\section{NOTES:}

1. ***,**, *Statistically significant at the $1 \%, 5 \%$ and $10 \%$ level respectively.

2. The t-statistics of coefficient estimates appear in parentheses.

3. The standard errors of the coefficient estimates are heteroscedasticity consistent.

larger and statistically more important.

Table 6 shows the regression results for EASTASIA in the period 1960-1999. In this case, the negative coefficient of INY is barely significant at the 10 percent level only in the 5- year panel. As expected from the analysis above, there is very weak evidence of conditional $\beta$-convergence in EASTASIA following the financial crisis and the economic slowdown in the second half of the 1990s. Yet, economic openness is still an important variable that contributes positively to economic growth in EASTASIA and is significant in the 5- and 10-year panels at 
the 5-and 1 percent level respectively. Population growth is only significant at the 5 percent level in the single regression for the entire period, but not in the two panels. Government spending is also statistically insignificant in the two panels. However, as was the case in Table 5, the two dummies for the 1980s and 1990s are statistically significant at the 5- and 1 percent level respectively. Notice that the 1990s decade has the strongest negative impact in Table 6 than in Table 5 (i.e., compare -6.979 versus -5.154). A plausible reason for this result is that the financial crisis had a stronger impact in East Asia than in the APEC region as a whole.

In summary, comparing the results in Tables 3 and 4 with the results in Tables 5 and 6, its it clear that the evidence of conditional economic convergence in APEC and EASTASIA regions is stronger in the period 1960-1990 than in the period 1960-1999. We attribute the difference in these results to the financial crisis that plagued the East Asian economies in the late 1990s and caused economic divergence. Further, the evidence shows that this is more the case in EASTASIA than in the APEC(16) region. Despite this, openness to international trade is an important variable to sustain economic growth in the Asia-Pacific region.

\section{Conclusion}

In this paper we used the concepts of $\sigma$-convergence and $\beta$-convergence to evaluate empirically income convergence among a group of APEC countries and subsets of 10 EASTASIA and 5 ASEAN countries during the period 1960-1999. Because of the Asian financial crisis of the late 1990s, the analysis was carried out sequentially, first for the period 1960-1990, and then for the period 1960-1999.

The empirical findings show that there is weak evidence of income convergence for a group of APEC(17) countries when analyzed in 5- or 10-year subintervals from 1960 to 1990 in single equation cross section regressions. However, we find statistically significant evidence of real per capita GDP convergence either when the whole sample period $1960-1990$ is analyzed or when the 10-year sub-periods are pooled and estimated in panel growth regressions. These are more plausible results both because economic growth and convergence are long run phenomena and because panel methods deliver more efficient parameter estimates. Similar results hold for the EASTASIA group during this period, but not for the ASEAN group that shows evidence of income divergence.

For the period 1960-1999, there is evidence of weak conditional income convergence 
in a group of APEC(16) countries, and this evidence becomes much weaker for the EASTASIA group of countries. The reason for these results is the negative effects of the Asian financial crisis on the Asia-Pacific region in general, and on East Asia in particular.

Macroeconomic stability and economic openness turn out to be statistically important factors and have the expected positive effect on economic growth in the APEC countries. Indeed, in most of the estimated models, the variable that is consistently the most significant is economic openness.

Of the other explanatory variables, population growth had the theoretically expected negative effect on economic growth as it is found in other studies on empirical growth. Government spending also had a negative effect on economic growth but it is not as statistically significant as is population growth. Our results on government spending are only indicative. Due to lack of data availability, in our study government spending is a proxy for government consumption expenditures. More detailed analysis is required to obtain more definitive results of the effects of the different components of government spending on economic growth. We intend to pursue this in future research.

The main policy implications that emerge from the empirical results of this paper is that if the Asia-Pacific countries wish to achieve high economic growth they should pursue policies that promote free trade and economic openness as well provide an anchor of economic stability by means of policies that keep inflation low. Financial crises have a negative effect on economic growth and convergence and, if possible, should be avoided by proper policy action.

\section{Acknowledgements}

The first author is grateful for partial financial support from the Social Sciences and Humanities Research Council of Canada (Grant No. 410-2000-1091). We would like to thank two anonymous referees and the editor of this Journal for constructive criticism and suggestions. Also we are grateful to Arman Mansoorian for valuable comments and suggestions, and Stratos Tselepis and Brennan Thompson for excellent research assistance. All remaining errors are our own.

Received 12 September 2001, Accepted 17 August 2002 


\section{References}

Barro, R.J. (1991), "Economic Growth in the Cross Section of Countries", The Quarterly Journal of Economics, 106: pp. 407-443.

Barro, R.J. and Sala-i-Martin, X. (1991), "Convergence Across States and Regions," Brookings Papers on Economic Activity, 1: pp. 107-158.

Barro, R.J. and Sala-i-Martin, X. (1992), "Convergence", Journal of Political Economy, 100: pp. 223-251.

Barro, R.J. and Sala-i-Martin, X. (1995), "Economic Growth,” New York: McGraw-Hill Inc.

Barro, R.J. and Lee, J.W. (1996), "International Measures of Schooling Years and Schooling Quality", American Economic Review, Papers and Proceedings, 86: pp. 218-223.

Baumol, W.J. (1986), "Productivity Growth, Convergence and Welfare: what the LongRun Data Show," American Economic Review, 76: pp.1072-1085.

Ben David, D. (1993), "Equalizing Exchange; Trade Liberalization and Income Convergence," The Quarterly Journal of Economics, 108: pp. 653-680.

Cass, D. (1965), "Optimum Growth in an Aggregative Model of Capital Accumulation," Review of Economic Studies, 32: pp. 223-240.

Cheshire, P. and Carbonaro G. (1995), "Convergence/Divergence in Regional Growth Rates: An Empty Black Box?," R.W. Vickerman, H.W. Armstrong Eds, Convergence and Divergence Among European Regions, European Research in Regional Science, London, Pion, pp. 89-111.

DeLong, G. (1988), "Productivity Growth, Convergence, and Welfare: Comment," American Economic Review, 78: pp. 1138-1159.

Fisher, S. (1986), "Lessons from East Asia and the Pacific Rim," Brookings Papers on Economic Activity, 2: pp. 345-350.

Industry Canada (1997), "The Asia Pacific Boom: Whats is in it for Canada," Micro, 4: Spring 1997.

Islam I. and Chowdhury, A. (1997), “Asia-Pacific Economies: A Survey,” London and New York: Routledge Press.

Koopmans, T.C. (1965), "On the Concept of Optimal Economic Growth," in the Econometric Approach to Development Planning, Amsterdam: North Holland.

Krugman, P. (1991), "Increasing Returns and Economic Geography," Journal of Political Economy, 99: pp. 483-499.

Levine, R. and Renelt, D. (1992), "A Sensitivity Analysis of Cross-Country Growth Regressions," American Economic Review, 82: pp. 942-963.

Lucas, R.E. Jr. (1998), "On the Mechanics of Economic Development," Journal of Monetary Economics, 22: pp. 3-42.

Neven, D. and Gouyette, C. (1995), "Regional Convergence in the European Community," Journal of Common Market Studies, 33: pp. 47-65. 
Romer, P.M. (1986), “Increasing Returns and Long-Run Growth,” Journal of Political Economy, 94: pp. 1002-1037.

Sapir, A. (1992), "Regional Integration in Europe," The Economic Journal, 102: pp. 14911506.

Sala-i-Martin, X. (1996), "Regional Cohesion: Evidence and Theories of Regional

Growth and Convergence," European Economic Review, 40: pp. 1325-1352.

Sherwood-Call, C. (1996), "The 1980s Divergence in State per Capita Incomes: What Does it Tell Us," Federal Reserve Bank of San Francisco, Economic Review, pp. 14-25.

Solow, R.M. (1956), "A Contribution to the Theory of Economic Growth," Quarterly Journal Of Economics, 70: pp. 65-94.

Suchs, J., (1997), "The Limits of Convergence," The Economist, June 14 1997.

Tamura, R. (1991), "Income Convergence in an Endogenous Growth Model," Journal of Political Economy, 70: pp. 522-540.

World Bank (1993), "World Bank Policy Research Report: The East Asia Miracle, Economic Growth and Public Policy," New York: Oxford University Press.

World Bank (1995) "World Development Report 1995: Workers in an Integrating World," New York: Oxford University Press.

Yamazawa, I. (1992), "On Pacific Economic Integration," The Economic Journal, 102: pp. 1519-29. 